\title{
THE ORGANIZATIONAL CULTURE AND VALUES ALIGNMENT MANAGEMENT IMPORTANCE FOR SUCCESSFUL BUSINESS
}

\author{
Nicholas Van-Eerven Ludolf ${ }^{1}$, Marcela do Carmo Silva ${ }^{1}$, Carlos Francisco Simões Gomes ${ }^{1}$, \\ Valmir Martins Oliveira²
}

1 Fluminense Federal University; 2 Universidad Mayor

\begin{abstract}
The main objective of this study was to carry out an organizational culture diagnosis in a shipyard, verifying the alignment degree between personal and organizational values. For data collection, a structured questionnaire was adopted and it was answered by 104 employees. In this questionnaire, the employees pointed out the main values cultivated by the company and by themselves. The results showed that there is a significant misalignment between organizational and personal values and an organizational culture based on values that aim at the self-interest of the organization and not the common good. The background of this article is to demonstrate the importance of the diagnosis and management of the organizational culture. To provoke a reflection on the importance of a culture that aims at the common good and not only the financial interest for a select group; not as an altruistic thinking, but as a strategy for organizational sustainability.
\end{abstract}

Keywords: Organizational Culture; Consciousness Levels; Values Alignment. 


\section{INTRODUCTION}

Large organizations fraction presents procedures with an organized structure, organized positions and well defined objectives. However, despite the existence of this formal organization, there is an informal organization with its own hierarchy, power structure, and peculiar way of doing things. In this way, the hierarchy and procedures are adapted to the individuals who exercise them. Thus, formal organization is modified through these adjustments, forming the culture that is being disseminated among employees and incorporating the organization. The culture of an organization is constantly changing. Ghinea (2015) observes that external and internal factors are constantly changing the culture.

Edgar Schein (2004) points out the need to consider the cultural dimension to diagnose the environment and to understand which forces act in groups and organizations. He states that culture, while being an abstraction, is a force capable of causing great impact in the social and organizational spheres. The author further argues the close relationship between culture and leadership, claiming they are on both sides of the same coin. For this author the organizational culture is the main identity of an organization.

\subsection{Problem situation and objectives}

Jourdain et Chênevert (2015) highlight that one of the great mistakes that leads organizations to fail in the long term is that they do not monitor their cultures. Value management can be used to support continuous improvements in organizational performance and to develop long-term sustainability. Russo et al. (2012) discuss that the knowledge and periodic diagnosis of the organizational culture are essential for the implementation of strategies aimed at improving the performance of the organization. In the midst of increasingly competitive and dynamic scenarios; managers need to know what aspects of culture can lead to improved outcomes (Lee, Joongwha et Byung, 2015).

This purpose of this article is to perform an organizational culture diagnosis in a shipbuilding sector company located in the city of Niterói; as well as to verify the alignment between the values cultivated by the organization under study and the values cultivated by its employees in the light of Barrett' seven level of consciousness model (2006). Three specific objectives can be highlighted: identify the main organizational culture formative values, its distribution along the seven levels of consciousness; identify the main values cultivated by employees, their distribution across the seven levels of consciousness and; confront the values cultivated by employees with organizational values and verify the degree of alignment between both parties.
The article is composed of an introduction, followed by a review of the literature. Section 3 presents the methodological procedures used and section 4 analyses research results. Finally, at section 5, there are the conclusions.

\section{LITERATURE REVIEW}

Serpa (2015), Stride et Higgs (2014) and Kang (2013) point to the growth of literature research related to values at work and take the view that the staff values alignment with organization values can bring positive results for improving the company's performance. Among these values, employees' commitment is the greatest. Some scholars bring light to the close relationship between culture and human behaviour. Calling attention to the business environment, Zago et Retour (2013) observe culture functions as a collective perceptual filter that influences the choices and behaviours of a particular company, and can be configured as an organizational competency determining factor; as a unique and inimitable intangible asset.

Buuren, Eshuis et Bressers (2015) analyse that the adoption of organizational values, aligned with concepts of innovation, tend to stimulate the company innovative process. Barrett (2014) points out that organizational culture management through values can be used to support continuous performance improvements and to develop long-term sustainability. Values management can understand the process of measuring, monitoring and responding to the values and behaviours that form the organizational culture, since this culture is adjusted to meet organizational interests and is capable of sustaining high performance and leading to mission (Idris, Nita et Godwin, 2015).

Massimi et Gontijo (2015) emphasize the importance of considering the different periods of the Brazilian history and its peculiarities in terms of political and economic aspects, among others that can modify people's customs, beliefs and values. In an exploratory case study of a Brazilian company, Souza et Nardi (2015) identified some Brazilian culture features present in the company's culture: high power concentration, loyalty among the members of the organization, paternalism, flexibility and "the Brazilian way".

In the values sphere, Schwartz (1994) underscores that personal values are constituted by desirable goals adopted by an individual life guide with respect to their attitudes and behaviours. They are life principles that vary in terms of importance and guide human beings ways act. The set of values and beliefs in groups are the foundations of their culture. Santos et Davel (2015) point to improvisation as a cultural factor that is present in the daily life due to the fact the current structures and norms are inadequate to the "imponderables of real life": improvisation can bring benefits to 
the organization; however, it should not become a general rule for organizational practices.

\subsection{Richard Barrett's Model}

The consciousness seven levels' model was created from Maslow's hierarchy of needs, whose could be transposed into a framework of consciousness (Barrett, 2014) aligned at Table 1. The consciousness levels, in which we operate, are directly influenced by ego and soul needs. According to the model seven, well-defined stages can be distinguished in personal consciousness development. Each stage is directly linked to a particular human existential need. The seven existential needs are human motivation sources. Individuals evolve in consciousness matters by learning to govern these needs.

Table 1. From Maslow's needs to Barrett consciousness

\begin{tabular}{|c|c|}
\hline Maslow (needs) & $\begin{array}{c}\text { Barrett (consciousness } \\
\text { levels) }\end{array}$ \\
\hline Self-actualization & 7 Service \\
\hline & 6 Making a difference \\
\hline Know and understand & 5 Internal Cohesion \\
\hline Self-esteem & 4 Transformation \\
\hline Love \& Belonging & 3 Self-esteem \\
\hline Safety & 1 Survival \\
\hline Physiological & \\
\hline
\end{tabular}

Source: Adapted from Barrett (2014, p. 460).

After aligning Marrow's and Barrett's studies, the seven stages in the development of personal consciousness are shown in the Figure 1.

\begin{tabular}{|c|c|}
\hline \\
\hline
\end{tabular}

Figure 1. The seven stages in the development of personal consciousness

Source: Adapted from Barrett (2006, p.12).

The first three levels focus on self-interest (satisfying the needs of the ego). The last three levels focus on the common good (meeting the needs of the soul). The fourth level represents the transformation of self-interest for the common good: this is the level where individuals begin to free them- selves from their fears related to survival and need to be loved and respected. Ego-related fears make individuals believe that they never have enough; with the elapsing of time, individuals will have the feeling of never having the money, love and respect they need to be happy, even if they have them.

Individuals operating exclusively on the first three levels of consciousness are unable to break free of their ego-related fears and live a dependence-based existence. They depend on others to feel safe, loved and respected. On the other hand, individuals who operate exclusively on the last three levels of consciousness tend to lose their skills necessary to satisfy their physical, relationship and self-esteem needs: they have not created the necessary basis for acting in the real world. According to Barrett (2014), individuals who desire to be winners in the world must learn how to satisfy all their needs by operating in what he calls the spectrum of total consciousness where the individuals' consciousness can embrace the seven levels of his model.

Groups can be defined as a set of individuals who share the same purpose. Organizations are included within this definition. Thus, the consciousness seven-level model can also be applied to them (Figure 2).

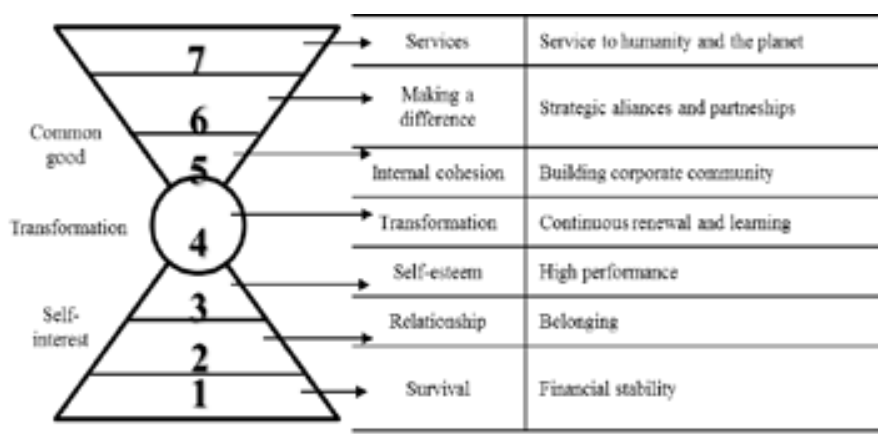

Figure 2. The seven stages in the development of organizational consciousness

Source: Adapted from Barrett (2006, p. 16)

Starting from an evolutionary perspective, the first three stages of the development of group consciousness represent the appearance and development of the ego. At these stages only leadership participates in decision making. The last three stages demonstrate the emergence and unfolding of the soul of the group. At these levels the collective interest of all members of the group is sought. The fourth stage can be understood as a search for the alignment of the needs of the ego with the needs of the soul; leadership interests are aligned with the interests of group members. Barrett (2014) analyses that the most successful groups are those who develop a consciousness that encompasses all levels of the model. These are organizations that can sustain themselves in the long run. Each identified value can be allocated to a level of consciousness. Table 2 shows an example 
Table 2. Seven levels consciousness values allocation

\begin{tabular}{|c|c|c|c|}
\hline Level & Motivation & Positive Values (P) & Excessive Focus (L) \\
\hline 7 & Services & Social responsibility, future generations, compassion & - \\
\hline 6 & Making a difference & Mentoring, community involvement, environmental awareness & - \\
\hline 5 & Internal cohesion & Confidence, commitment, trust, integrity, passion & - \\
\hline 4 & Transformation & Adaptability, empowerment, personal growth & - \\
\hline 3 & Self-esteem & Quality, best practices, pride in performance & Bureaucracy, complacency \\
\hline 2 & Relationship & Open communication, customer satisfaction, friendship & Manipulation, blame \\
\hline 1 & Survival & Financial stability, profit, employee health & Control, corruption, greed \\
\hline
\end{tabular}

Source: Adapted from Barrett (2006, p. 22)

Table 3. Significance of the different levels of cultural entropy

\begin{tabular}{|c|c|}
\hline Cultural entropy & Impact \\
\hline$\geq 40 \%$ & $\begin{array}{c}\text { Critical Issues - Requiring cultural and structural transformation, selective changes in leadership, leadership } \\
\text { mentoring/coaching and leadership development }\end{array}$ \\
\hline $30 \%-39 \%$ & $\begin{array}{l}\text { Serious Issues - Requiring cultural and structural transformation, leadership mentoring/coaching, and leadership } \\
\text { development }\end{array}$ \\
\hline $20 \%-29 \%$ & Significant Issues - Requiring cultural and structural transformation, and leadership coaching \\
\hline $10 \%-19 \%$ & Minor Issues - Requiring cultural and/or structural adjustment \\
\hline$<10 \%$ & Prime - Healthy funcitioning \\
\hline
\end{tabular}

of how values/behaviours can be allocated.

Potentially limiting values and beliefs occur when beliefs based on ego-related fears of leaders or employees lead to actions that undermine the common good. Allocation of values can be used to measure the personal awareness of the individual components of the company, to measure current organizational culture perceived by them and to measure the organizational culture desired by its members. The results also allow us to verify the alignment of the personal values of the employees with the values of the current culture, as well as the alignment of the values of the current culture with the components of the desired culture. Another extremely relevant fact that can be measured is cultural entropy, which is defined as the proportion of energy in a human system (organization) that is consumed by non-productive activities (Barrett, 2006: 21). Tanno, Kurashima et Watanabe (2011) corroborate Barrett when they analyse that motivational control in motivational factors can be incorporated into behavioral theories as variables that alter the effectiveness of reinforcement.

It can be understood as the measurement of the internal frictions generated by relationship problems, structural misalignments and other present organization problems. Table 3 demonstrates the significance of the organization entropy level. Entropy is calculated by the number of limiting values divided by the total number of identified values, whether personal, present in the current culture or in the desired culture by the organization members.

\section{METHODOLOGY}

The research strategy adopted to achieve the objectives was the case study, because in the first place, as Gray (2012) states, it is a strategy used when there are many contextual variables, such as the economic and political conjuncture, culture, momentum, among others, which are organizational environments, making a purely experimental approach unfeasible. Yin (2003) conceptualizes case study as an empirical investigation that addresses a contemporary phenomenon within its real context when the delimitation between context and phenomenon is not clear. According to its objectives, this study can be classified as descriptive research. As Hedrick, Bickman et Rog (1993) observe, the purpose of descriptive work is to construct a picture of the phenomenon as it occurs naturally, and it may include the comparison of data against some pattern and show how things relate to each other. One of the study's proposals is to identify the main current and desired personal and organizational values, classify them and establish comparisons and relationships between them. Besides the descriptive character, it can also be classified as explanatory, since it seeks to explain what was described above, as highlighted by Gray (2012).

Yin (2003) analyses the case study can be used as a quantitative and qualitative method, although it is used as a qualitative study. The present research can be characterized as a quantitative research since, on the one hand, it seeks to collect data through structured questionnaires (objectivist vision) and to group them and to study them based on statistical models (data based on numbers). However, it can also be characterized 
Brazilian Journal of Operations \& Production Management

Volume 14, Número 1, 2017, pp. 272-280

DOI: 10.14488/BJOPM.2017.v14.n2.a15 as a qualitative research, since, on the other hand, it seeks to perform the analysis of documents that are characterized by a constructivist epistemological position. The main research instrument adopted was the questionnaire with closed questions, constructed in light of Barrett's seven-level model of consciousness (Barrett, 2006). According to Flick (2013), questionnaires are appropriate to a study when: (i) it is possible to formulate a sufficient number of questions unambiguously from existing knowledge about the research question; (ii) there is a large number of participants. The questionnaire presented three stages. In the first one the respondent informed some important data for the research, such as schooling level, sex, etc. Care was taken to preserve the identity of the respondent in order not to inhibit him to respond in a sincere way. In the second stage the participant chose, among 70 personal values, the 10 values with which he most identifies himself by marking them with an " $X$ ". In the third and last stage, the participant chose, among 70 organizational values presented, those which, in his opinion, most identified with his company by marking them with an " $X$ ". Further data processing allowed the identification of the alignment degree between these two dimensions of values as well as the distribution of organizational values among the seven levels of consciousness. Another form of data collection used was document analysis. This method served to identify the organizational values desired by the organization. These figures are posted on their website.

After data collection through questionnaires, a data tabulation process was carried out where personal and organizational values were ordered per the number of votes received. In this way, the ten organizational values and the ten most voted personal values were identified. Finally, after identifying the main organizational and personal values, their distribution was carried out through the levels of consciousness, and their degree of alignment was verified. Because it is a population of 3,500 individuals, a sample of 252 individuals would be necessary to obtain a margin of error of $5 \%$ and a confidence level of $90 \%$. The first objective was to obtain a minimum sample of 252 questionnaires answered; however, this objective became impracticable due to the closure of the activities of the yard during the course of the research, making access difficult to the workers. The number reached was 104 questionnaires answered, representing a margin of error of approximately $10 \%$ and a confidence level of $95 \%$.

\section{PRESENTATION AND RESULTS ANALYSIS}

\subsection{Current organizational values}

Table 4 shows the top ten current organizational values according to the field research conducted through the questionnaires, as well as the number of votes received and the level of consciousness to which they belong.
Table 4. Questionnaires current organizational values

\begin{tabular}{|c|c|c|}
\hline Current organizational values & Votes & $\begin{array}{c}\text { Conscious- } \\
\text { ness level }\end{array}$ \\
\hline 1. There is lack of confidence (L) & 59 & 2 \\
\hline $\begin{array}{c}\text { 2. Exclusively focused on financial } \\
\text { performance }\end{array}$ & 57 & 1 \\
\hline 3. Hierarchic (L) & 47 & 3 \\
\hline 4. Focused on productivity & 45 & 3 \\
\hline 5. Focused on short-term (L) & 41 & 1 \\
\hline 6. Fulfilled minimal Law & 35 & 1 \\
\hline 7. Prize obbedience (L) & 31 & 2 \\
\hline 8. See people as resources & 29 & 1 \\
\hline 9. Work as a team & 27 & 5 \\
\hline 10. Excessive control (L) & 27 & 3 \\
\hline
\end{tabular}

Figure 3 shows the distribution of the top ten current organizational values distributed across the seven levels of consciousness. A large concentration of values can be seen in the lower three levels of consciousness (self-interest) and a large number of potentially limiting values. The perforated balls represent potentially limiting values and the floods balls represent positive values.

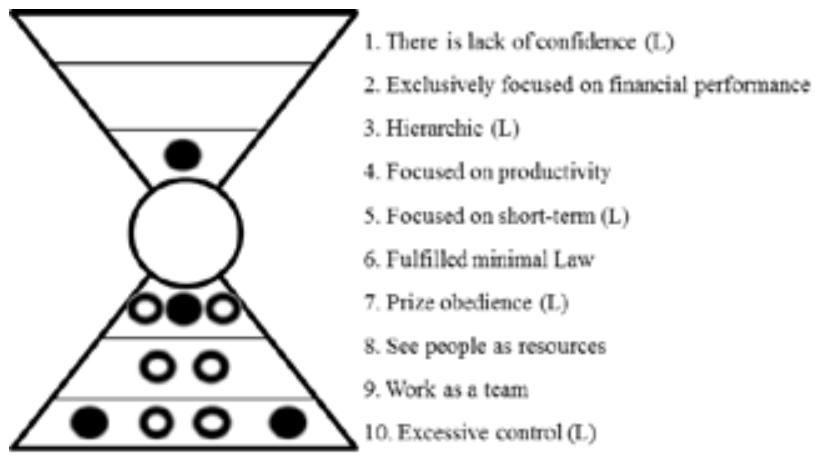

Figure 3. Questionnaires current organizational values versus consciousness level

A large concentration of values (9 out of 10) can be observed in the three lower levels of consciousness, demonstrating the organization acts with a focus on self-interest. As the model points out, these are organizations that have not been able to abandon their fears (6 limiting values) related to survival, relationships and self-esteem. Only leaders participate in the decision-making process. Among the ten major values, six are potentially limiting. Two of these, "there is a lack of confidence" (the most voted with 59 votes) and "prize obedience" reveal an organization that attaches great importance to relationships, generating differentiated treatments according to the bonds of friendship, family ties and others.

"Hierarchic", being the third highest value with 47 votes, shows the great differentiation in terms of the treatment given to the employee due to its hierarchical level and the 
non-participation of the workers in the decision making processes, which is common in companies of this nature. The highest concentration of values appears at the first level of consciousness, showing great concern in terms of the organization with its own survival ("exclusively focused on financial performance" as the second most voted value, with 57 votes) and concern for law enforcement. However, at this level there are two limiting values ("see people as resources" and "focused on short term"), these values evidencing the lack of development policies, valorization and retention of employees. Only one value presented in one of the three higher levels of consciousness focused on the common good: "work as a team" and it was next to "excessive control", which was the least voted among the top ten, with 27 votes.

\subsection{Personal values}

Table 5 shows the ten personal values most voted, according to the field survey conducted through the questionnaires, as well as the number of votes received and the level of consciousness to which they belong.

Table 5. Most voted personal values

\begin{tabular}{|c|c|c|}
\hline Personal values & Votes & $\begin{array}{c}\text { Consciousness } \\
\text { level }\end{array}$ \\
\hline 1. I like to learn & 56 & 4 \\
\hline 2. I seek quality of life & 46 & 4 \\
\hline 3. I like to work in a team & 40 & 5 \\
\hline 4. I am responsible & 40 & 4 \\
\hline 5. I adapt the changes well & 34 & 4 \\
\hline 6. I worry about my career & 34 & 3 \\
\hline 7. I cultivate my friendships & 30 & 2 \\
\hline 8. I always seek the truth & 28 & 5 \\
\hline 9. Stability at work is important (L) & 28 & 1 \\
\hline 10. Health and safety matters & 28 & 1 \\
\hline
\end{tabular}

Figure 4 shows the distribution of the ten most voted personal values by the seven levels of consciousness.
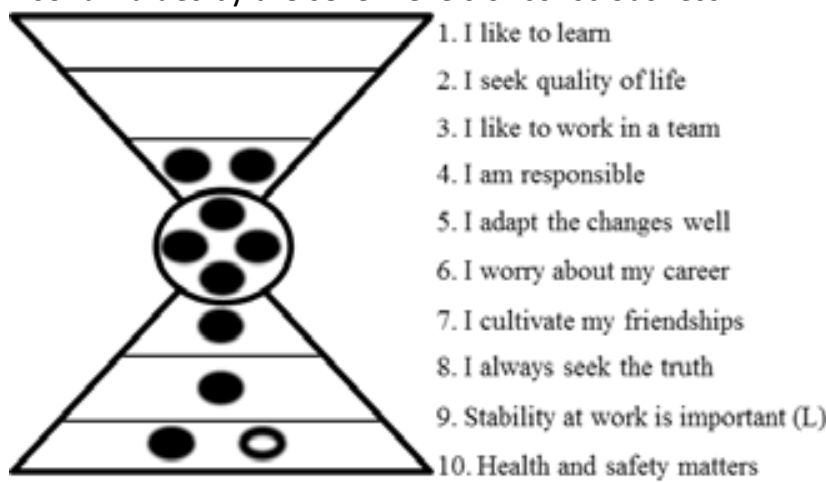

Figure 4. Most voted personal values versus consciousness level.
The ten most voted personal values are distributed across five levels of consciousness, with no such values at levels six and seven. There is a great concentration of values at level four (transformation). Of the five most voted values, four belong to this level, as shown in Table 5, which demonstrates the willingness of employees to free themselves of their fears related to the lower levels. They seek self-fulfilment and higher quality of life at work and are receptive to change. They want to be heard and participate more actively in decisions. There are two values at level 5 , indicating that employees seek to find meaning for their work and an alignment between their values and organizational values, valuing the search for truth and teamwork. The value "stability at work is important" can become a limiting value; however, it is the only one among the other the most voted positive values.

\subsection{Desired culture values}

Table 6 shows company's desired organizational values. The table values were obtained through the document of analysis method. All are posted on the company's website. There were 11 observed values. Figure 5 shows the distribution of these values by the consciousness seven levels.

Table 6. Desired organizational values

\begin{tabular}{|c|c|}
\hline Current organizational values & $\begin{array}{c}\text { Consciousness } \\
\text { level }\end{array}$ \\
\hline 1. Social responsibility & 7 \\
\hline 2. Concern with the environment & 6 \\
\hline 3. Honesty & 5 \\
\hline 4. Teamwork & 5 \\
\hline 5. Integrity & 5 \\
\hline 6. Responsibility & 4 \\
\hline 7. Learning & 4 \\
\hline 8. Concerned with your image (L) & 3 \\
\hline 9. Operational excellence & 3 \\
\hline 10. Customer satisfaction & 2 \\
\hline 11. Employee health & 1 \\
\hline
\end{tabular}

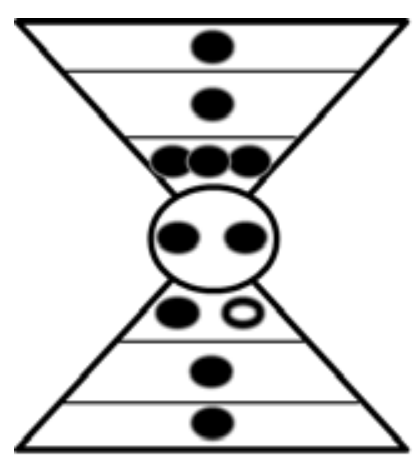

1. Social responsibility

2. Concern with the environment

3. Honesty

4. Teamwork

5. Integrity

6. Responsibility

7. Learning

8. Concerned with your image $(\mathrm{L})$

9. Operational excellence

10. Customer satisfaction

11. Employee health

Figure 5. Desired organizational values versus Consciousness level 
Figure 5 shows the company wants an organizational culture based on values distributed across all consciousness seven levels, most of which are at the higher levels, i.e. level 4 (transformation) onward. The company's interest in social and environmental issues is also verified. Values such as "social responsibility" and "concern with the environment" are desired by the organization. The great concentration of values in level 5 (internal cohesion) demonstrates the desire to build a shared vision of the future, aligning values between employees and organization, generating enthusiasm and commitment. "Learning" and "responsibility" are values belonging to level 4 (transformation) and demonstrate interest in the evolution of the company through knowledge and the desire to delegate more responsibility to employees.

\subsection{Verifying values alignment}
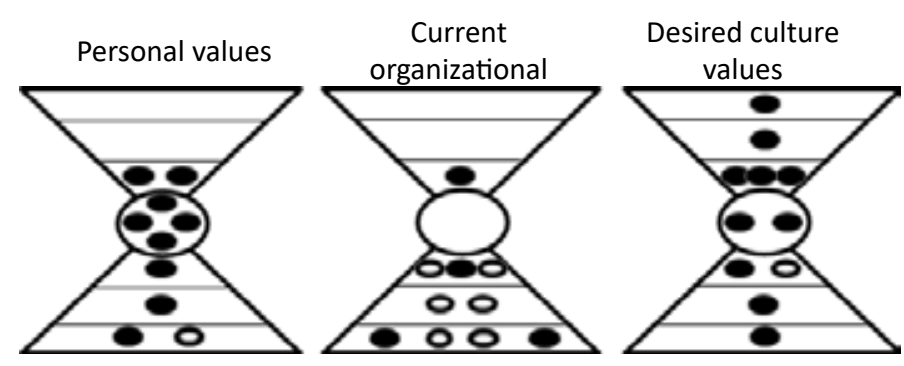

Figure 6. Compared three dimensions values

Figure 6 presents, side by side, the distribution across the consciousness seven levels to the desired personal, organizational, and organizational values respectively. A great misalignment can be noticed between personal values and current organizational values. While the top four personal values ("I like to learn", "I seek quality of life", "I like to work in a team", and "I am responsible") focus on levels four and five. The four most current voted organizational values ("there is lack of confidence", "exclusively focused on financial performance", "hierarchic" and "focused on productivity") are all distributed across the lower three levels of consciousness (self-interest), being two of these potentially limiting values. "Teamwork" is the only common value between the current personal and organizational values.

There is also a large misalignment between the current organizational values and organizational values desired by the company. The only value common to both categories is "teamwork". Most of the current organizational values ( 9 of 10 values) are in the three lower levels of consciousness (self-interest) while most of the desired organizational values ( 7 out of 11 values) are distributed between level 4 (transformation) and the three levels (common good). "Learning", "teamwork", "responsibility" and "health and safety matters" are values common to the personal values and organizational values desired, demonstrating there is an alignment between these two values categories. Most of the personal values (6 of the 10 values) are concentrated between levels 4 and 5 . The same can be verified for the desired organizational values where 5 of the 11 values are between 4 and 5 levels. However, for personal values, no value was found among the top 10 for levels 6 and 7, while two values for these levels appear in the desired organizational values. The relative alignment between the distribution of the 10 most voted personal values and the desired organizational values suggests the possibility that the organization can achieve the desired culture.

\subsection{Indexes}

Figures 7 and 8 present the percentage distribution of the vote for all voted values, not just the top 10, according to the seven levels of consciousness. The white bars represent the positive values $(P)$ and the black bars show that the potentially limiting values $(L)$ only exist in the first three levels of consciousness (self-interest). Therefore, for the first three levels, the percentage of votes received will be the sum between the percentage of positive values and the potentially limiting values for each level.

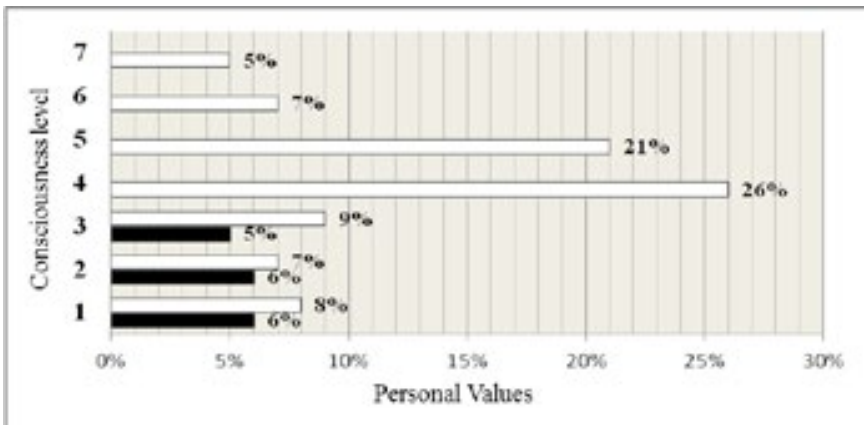

Figure 7. Personal values distribution by consciousness level

The distribution of values to the dimension of personal values shows a large concentration of values (47\%) between levels 4 (transformation) and 5 (internal cohesion), which demonstrates that employees are people willing to control their ego-related fears and become more independent of the lower needs. They seek: self-fulfilment, personal growth, and meaning for work. Forty-one percent of the values are distributed in the three lower levels and $17 \%$ of these values are potentially limiting. According to Table 3, the value of $17 \%$ for the number of potentially limiting values (entropy level) is considered a good result, requiring only some cultural and/or structural adjustments. 


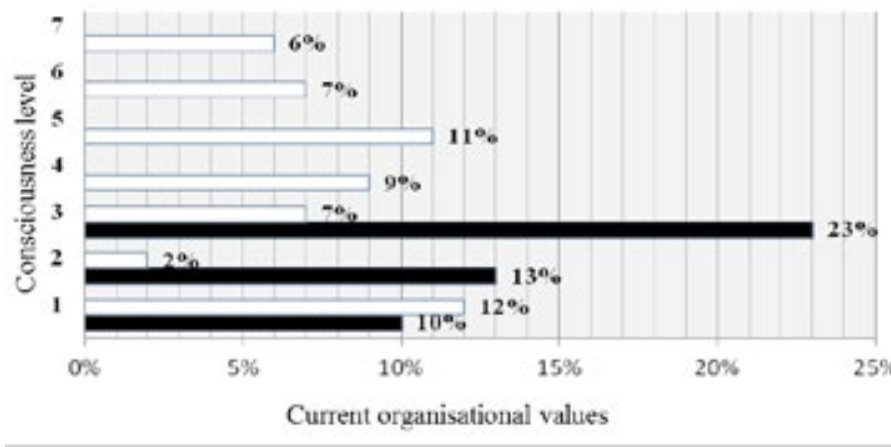

Figure 8. Current organizational values distribution by consciousness level

The current organizational values dimension has a large concentration of values $(67 \%)$ in the three lower consciousness levels; demonstrating organization adopts a culture based on a value structure focused on the first three levels of consciousness (self-interest). Another highlight is the high percentage of potentially limiting values (46\%). Figure 9 shows more clearly the percentage distribution of the vote for all voted values, not just the top 10 voted, according to the three highest levels of consciousness (common good), the fourth level of consciousness (transformation) and the three lower levels (self-interest). Table 7 presents BTI and entropy indices.

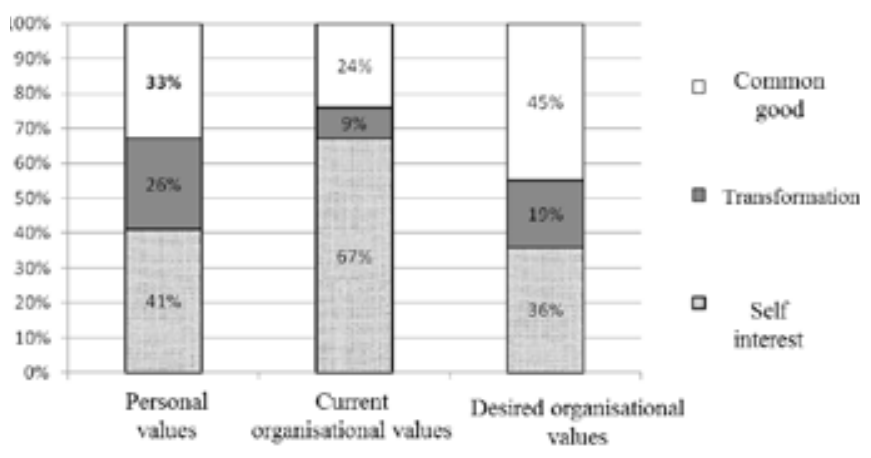

Figure 9. Organizational consciousness development distribution at three stages

Table 7. BTI and entropy indexes

\begin{tabular}{|c|c|c|}
\hline Personals & $\begin{array}{c}\text { Current } \\
\text { organizational }\end{array}$ & $\begin{array}{c}\text { Desired } \\
\text { organizational }\end{array}$ \\
\hline $\mathrm{BTI}=33-26-41$ & $\mathrm{BTI}=24-9-67$ & $\mathrm{BTI}=45-16-36$ \\
\hline Entropy $=17 \%$ & Entropy $=46 \%$ & - \\
\hline
\end{tabular}

BTI index is considered satisfactory for personal values dimension, since it presents a great majority of values $(59 \%)$ in the higher levels from level 4 . The same can be said in relation to the desired organizational values, presenting $64 \%$ of their values from the level 4 . The same cannot be said in relation to the current organizational values, since they present only $33 \%$ of their values allocat- ed in the upper levels from level 4 . The great majority of their values $(67 \%)$ is allocated to the three lower levels of consciousness (self-interest); of which $46 \%$ are potentially limiting values (entropy). According to table 3 , the index $46 \%$ for entropy is considered critical. For these cases, the model foresees activities such as structural changes, selective changes in leadership, application of mentoring and coaching and leadership development in cases such as this, where the current culture presents a large percentage of limiting values.

\section{FINAL DISCUSSIONS}

The results demonstrated that the company sustains an organizational culture based on a set of values strongly directed to the lower three levels of consciousness (self-interest), pointing to an organization driven by fear and lack of trust. It does not want to delegate power and responsibility. It wants to listen to and involve employees in the decision-making processes. They also prove to be an outcome-focused organization for shareholders. Companies with this focus have difficulty retaining talent and keeping their employees satisfied, enthusiastic and motivated. Employees are often highly stressed. The company has presented high monthly rates of absenteeism (30\%) and history of frequent strikes in recent years.

It has been found that the percentage of potentially limiting values is high, which points once again to a company that cannot free itself from its fears related to survival, relationships and self-esteem In order to reach higher levels of consciousness, seeking the alignment between the personal and organizational values and, in this way, promoting greater commitment and self-realization of human capital. It also creates an environment of greater confidence and enthusiasm, fostering learning and innovation, enabling the retention of talent and increasing productivity. The research pointed to a significant misalignment between personal values and the current organizational values and relative alignment between personal values and desired organizational values, suggesting the possibility that the organization may achieve the desired culture if it takes the necessary action. It can be seen from figure 5 that the desired organizational culture is rooted in a structure of values that are distributed across all seven levels of consciousness, most of which are at the higher levels, i.e. level 4 (transformation) onwards. The research shows that there is a large misalignment between the current organizational values and desired organizational values by the organization to support its strategies. In this scenario, considering the lack of commitment of the leaders in adopting and implementing the culture desired by the organization. 
Brazilian Journal of Operations \& Production Management

Volume 14, Número 1, 2017, pp. 272-280

DOI: 10.14488/BJOPM.2017.v14.n2.a15

\section{REFERENCES}

Barrett, R. (2006). A whole system approach to cultural transformation. Oxford: Elsevier.

Barrett, R. (2014). O novo paradigma da liderança: lidere a si mesmo, lidere os outros, lidere uma organização, lidere uma sociedade. Rio de Janeiro: Qualitymark.

Buuren, A. V.; Eshuis, J.; Bressers, N. (2015). The governance of innovation in Dutch regional water management: organizing fit between organizational values and innovative concepts. Public Management Review, Vol. 17, No. 5, pp. 679697.

Ghinea, V. M. (2015). Organizational culture dynamics factors that influence the organizational culture. Quality - Access to Success, Vol. 16, No. 146, pp. 63-70.

Gil, A. C. (1999). Métodos e técnicas de pesquisa social, 5 ed. São Paulo: Atlas.

Gray, D. E. (2012) Pesquisa no mundo real, 2 ed. Porto Alegre: Penso.

Hedrick, T. E.; Bickman, L.; Rog, D. J. (1993). Applied research design: a practical guide. California: Sage.

Hofstetter, H; Harpaz, I. (2015). Declared versus actual organizational culture as indicated by an organization's performance appraisal. International Journal of Human Resource Management, Vol. 26, No. 4, pp. 445-466.

Idris, K. M.; Nita, A. K.; Godwin, A. U. (2015). Impact of organizational culture on knowledge management process in construction. Asian Social Science, Vol. 11, No. 9, pp. 281-288.

Jourdain, G.; Chênevert, D. (2015). The moderating influence of perceived organizational values on the burnout-absenteeism relationship. Journal of Business and Psychology, Vol. 30, No. 1, pp. 177-191.

Kang, M. (2013). When an organizational message resonates with personal values of publics: implications for strategic communication management. Atlantic Journal of Communication, Vol. 21, No. 4, pp. 185-199.

Lee, J. L.; Joongwha, K.; Byung, P. (2015). Culture clashes in cross-border mergers and acquisitions: a case study of Sweden's Volvo and South Korea's Samsung. International Business Review, Vol. 24, No. 4; pp. 580-593.
Massimi, M.; Gontijo, S. R. (2015). History of psychological knowledge in Brazilian culture: weaving threads on the loon of time. History of Psychology, Vol. 18, No. 2, pp. 170-182.

Paschoal, T.; Alvaro, J. L.; Barreiros, J. P. (2015) The moderating effect of personal values in the relationship between working conditions and wellbeing. Revista de Psicologia Social, Vol. 30, No. 1, pp. 89-121.

Russo, M. G., et al. (2012). Correlacionando tipos de cultura organizacional com estratégias de remuneração utilizando a tipologia de Charles Handy. Revista Eletrônica de Administração, Vol. 73, No. 3, pp. 651-680.

Santos, L. A. N.; Davel, E. (2015). Improvisação como competência cultural: uma autoetnografia da atividade gerencial no setor público. Revista Gestão \& Conexões, Vol. 4, No. 1, pp. 91-115.

Schein, E. H. (2004). Organizational culture and leadership. San Francisco: Jossy-Bass.

Schwartz, S. H. A. (1994). Are there universal aspects in structure and contents of human values? Journal of social issues, Vol. 50, No. 1, pp. 19-45.

Serpa, S. (2015). The non-sharing of organizational culture: a case study examining the management perspective. Asian Social Science, Vol. 11, No. 10, pp. 221-230.

Souza, R. R. F.; Nardi, A. (2015). A percepção de traços notadamente brasileiros na composição de uma cultura organizacional. Gestão Contemporânea, Vol. 5, No. 1, pp. 69-92.

Stride, H.; Higgs, M. (2014). An investigation into the relationship between values and commitment: A study of staff in the U. K. charity sector. Nonprofit and Voluntary Sector Quarterly, Vol. 43, No. 3, pp. 455-479.

Tanno, T.; Kurashima, R.; Watanabe, S. (2011) Motivational control of impulsive behavior interacts with choice opportunities. Learning and Motivation, Vol. 42, pp. 145-153.

Yin, R. K. (2003). Case study research: design and methods, 2 ed., California: Sage.

Zago, C. C.; Retour, D. (2013). Cultura Organizacional: Nível coletivo constitutivo da gestão por competências. Gestão \& Produção, Vol. 20, No. 1, pp. 180-191. 